\title{
Induction of the multixenobiotic/multidrug resistance system in HeLa cells in response to imidazolium ionic liquids
}

\author{
Izabela Rusiecka` and Andrzej C. Składanowski ${ }^{\bowtie}$ \\ Intercollegiate Faculty of Biotechnology UG-MUG, Medical University of Gdańsk, Gdańsk, Poland
}

\begin{abstract}
The multixenobiotic/multidrug resistance (MXR/MDR) system controls transport of foreign molecules across the plasma membrane as a preventive measure before toxicity becomes apparent. The system consists of an efflux pump, $A B C B 1$, and/or a member of the $A B C C$ family. lonic liquids are broadly used solvents with several unique properties such as wide liquid range, negligible vapor pressure, good thermal and chemical stability and extraordinary dissolution properties for organic and inorganic compounds. Ionic liquids containing imidazolium ring are frequently used as solvents in drug synthesis. Constitutive and induced amounts of $A B C B 1$ and $A B C C 1$ proteins were estimated here by Western blotting and quantified by flow cytometry in HeLa cells exposed to three homologous 1-alkyl-3-methylimidazolium and one benzyl ring substituted salts. Aliphatic substituents in position 1 of the salts caused a weak toxicity but 1-benzyl ring was strongly toxic. An 8-day long treatment with $10^{-4} \mathrm{M}$ 1-hexyl-3-methylimidazolium chloride resulted in an about 1.5-fold increase of $A B C B 1$ level and over 2-fold increase of ABCC1 level. The amounts of both investigated $A B C$-proteins were linearly dependent on the length of the imidazolium ring side chain. Such distinctive changes of the amount of MXR/MDR proteins measured in cultured cells may be a useful marker when screening for potential toxicity of various chemicals.
\end{abstract}

Keywords: multidrug resistance, multixenobiotic resistance, imidazolium ionic liquids, flow cytometry, ABCB1, ABCC1

Received: 17 September, 2010; revised: 24 March, 2011; accepted: 08 May, 2011; available on-line: 17 May, 2011

\section{INTRODUCTION}

Vast quantities of newly synthesized compounds have been released to the environment for decades without sufficient control or proper evaluation of possible delayed toxic effects. Ionic liquids which are frequently used as solvents in organic synthesis are representatives of such compounds. They form salts with a melting point below room temperature. Cationic-type ones comprise a bulky organic cation paired with various anions (Welton, 1999). The entire group is referred to as technological "green solvents" because of a negligent hazard coming from unintended release due to an extremely low vapor pressure at high temperatures (Swatloski et al., 2001). Nevertheless, they are acknowledged as toxic agents (Stock et al., 2004; Zhao et al., 2007). Since early $1990 \mathrm{~s}$, the properties and solvating potential of ionic liquids have been actively investigated but little attention was paid to their presence in ready-to-use products i.e., drugs. The detection and estimation of residual sol- vents is of particular importance in quality control due to potential risk for human health (Liu \& Jiang, 2007). A search for specific biomarkers of ionic liquid-triggered effects and evaluation of the risk related to compound structure become now a challenge. A good biomarker to verify the effects of this group of compounds might be the response of the cell MDR/MXR system.

Originally related to drugs but later to general xenobiotics, the MDR/MXR system is a biological first line defense mechanism against foreign substances. It contains an efflux pump comprising ABCB1 (also denominated P-glycoprotein, P-gp) and/or other proteins from the ABCC subfamily (also denominated multiple resistance associated protein, MRP). ABC transporters are multidomain proteins comprising both transmembrane and intracellular nucleotide-binding structures. The hydrolysis of ATP delivers energy for ejection of compounds out of the cell (Higgins, 1992).

ABCB1 is a 1280 -amino-acid $(170 \mathrm{kDa})$ protein encoded by the $A B C B 1$ gene (Endicott \& Ling, 1989). It is expressed in epithelial cells of the kidney, liver and pancreas, intestinal mucosa and in capillaries of the brain and testis (Cordon-Cardo et al., 1990). ABCB1 plays there a xenobiotic-controlling role and is inhibited by calcium channel blockers (Gottesman \& Pastan, 1993). When expressed constitutively, it confers intrinsic drug resistance on cancer cells. ABCB1-associated resistance to drugs can be acquired during a contact with many other chemicals. A prolonged exposure to cytotoxic factors in vitro may lead to the selection of cells with $A B C B 1$ gene amplification. ABCB1 expression de novo may also be induced by a short-term exposure to UV irradiation (Uchiumi et al., 1993), chemotherapeutic drugs (Chaudhary \& Roninson, 1993) and other stressors (Chin et al., 1990). Generally, substrates for ABCB1 have an amphipatic character and molecular mass ranges between 300 and $2000 \mathrm{Da}$ (Seelig, 1998).

ABCC1 is a member of the distinct C-subfamily of ABC proteins. Structurally, the complete molecule (190 $\mathrm{kDa}$ ) has three transmembrane domains, each containing 17 peptide helices, followed by two nucleotide-binding domains (Cole et al., 1994). It is a polytopic membrane transporter of considerable clinical importance as it con-

\footnotetext{
«e-mail: acskla@gumed.edu.pl

^Present address: Department of Pharmacology, Medical University of Gdańsk, ul. Dębowa 23, 80- 04 Gdańsk, Poland

Abbreviations: ABC, ATP-binding cassette (generic); $A B C B 1$, ATP binding cassette (transporter) B1; ABCC1, ATP-binding cassette (transporter) C1; DMEM, Dulbecco modified Eagle's medium; IIL, imidazolium ionic liquids (general), for compounds $\mathrm{BMIMCl}$, BeMIMCI, EMIMCl, HMIMCl see Table 1; MDR, multidrug resistance; MXR, multixenobiotic resistance; PBS, phosphate-buffered saline; TBS, Tris-buffered saline
} 
Table 1. The imidazolium ionic liquids (IIL) investigated in this study

\begin{tabular}{|c|c|c|c|c|c|}
\hline Systematic name & Abbreviation & $\begin{array}{l}\text { Molecular } \\
\text { formula }\end{array}$ & $\begin{array}{l}\text { Molecular- } \\
\text { mass }\end{array}$ & CAS Reg. No. & Chemical formula \\
\hline $\begin{array}{l}\text { 1-ethyl- } \\
\text { 3-methylimidazolium } \\
\text { chloride }\end{array}$ & EMIMCl & $\mathrm{C}_{6} \mathrm{H}_{11} \mathrm{ClN}_{2}$ & 146.62 & 65039-09-0 & \\
\hline $\begin{array}{l}\text { 1-butyl- } \\
\text { 3-methylimidazolium } \\
\text { chloride }\end{array}$ & $\mathrm{BMIMCl}$ & $\mathrm{C}_{8} \mathrm{H}_{15} \mathrm{ClN}_{2}$ & 174.68 & 79917-90-1 & \\
\hline $\begin{array}{l}\text { 1-hexyl- } \\
\text { 3-methylimidazolium } \\
\text { chloride }\end{array}$ & $\mathrm{HMIMCl}$ & $\mathrm{C}_{10} \mathrm{H}_{19} \mathrm{ClN}_{2}$ & 202.73 & 171058-17-6 & \\
\hline $\begin{array}{l}\text { 1-benzyl- } \\
\text { 3-methylimidazolium } \\
\text { chloride }\end{array}$ & BeMIMCl & $\mathrm{C}_{11} \mathrm{H}_{13} \mathrm{ClN}_{2}$ & 208.69 & $36443-80-8$ & \\
\hline
\end{tabular}

fers multidrug resistance and reduces drug accumulation in tumor cells. It is also an efficient transporter of organic anions such as drugs conjugated with glutathione, sulfates or glucuronates, and anticancer drugs, such as anthracyclines or mitoxantrone (Deeley \& Cole, 2006).

In this study, three homologues of 1-alkyl-3-methylimidazolium chloride together with 1-benzyl derivative (Table 1) were tested. These compounds are useful in medical and pharmaceutical applications (Mizuuchi et al., 2008). We found that they have a high ability to induce the MDR/MXR system in cell culture.

\section{MATERIALS AND METHODS}

Cell lines, culturing and treatment. Cell lines: MCF7 (human breast cancer), HeLa (human cervical cancer) and HEK293 (human embryonic kidney) were cultivated in DMEM with $4.5 \mathrm{~g}$ glucose/1 (Sigma, Germany). Medium contained 10\% fetal bovine serum
(Gibco, USA) and 1\% PEN/STREP (Sigma, Germany). HEK293 were obtained from the American Type Culture Collection and the other lines were from the local cell bank (www.biology.pl/biomobil). Original lines were checked for the presence of mycoplasma. Cells were seeded in $150 \mathrm{~mm}$ dishes and cultured until about $70 \%$ confluence. Media were exchanged for fresh ones supplemented with $10^{-6}-10^{-4} \mathrm{M}$ ionic liquids (EMIMCl, BMIMCl, HMIMCl, BeMIMCl, all from Merck, Germany; for explanation see Table 1). The incubation was continued for 3-8 days (depending on the experiment setup) with every second day exchange for fresh supplemented medium. Thereafter cells were scrapped in ice-cold PBS/proteases inhibitors cocktail, lysed in $0.1 \%$ Triton X-100 in PBS, centrifuged at 14000 r.p.m. for 5 min and the supernatant was subjected to Western blot analysis.

HeLa cell viability assay. The MT'T assay was based on the protocol described by Park et al. (1987). MTT (5 mg/ml) was dissolved in PBS, sterilized by fil- 
tration through a $0.22 \mu \mathrm{m}$ Millipore ${ }^{\circledR}$ filter and stored at $4^{\circ} \mathrm{C}$. Cells were seeded at a density of $10^{4}$ cells $/$ well in a 96-well plate in $100 \mu \mathrm{l}$ of culture medium and allowed to grow for $24 \mathrm{~h}$ before adding ionic liquids at $10^{-6}-10^{-4}$ $\mathrm{M}$ final concentration. After $24-72 \mathrm{~h}$ of treatment, the cells were washed twice in PBS and then $100 \mu \mathrm{l}$ of 0.5 $\mathrm{mg} / \mathrm{ml} \mathrm{MTT}$ in serum free medium was added into each well. The incubation was continued for $3 \mathrm{~h}$ at $37^{\circ} \mathrm{C}$ to allow MTT metabolism. The formazan produced was dissolved in $100 \mu \mathrm{l}$ of acidified isopropanol and absorbance was measured at $570 \mathrm{~nm}$ using a BioTek ${ }^{\circledR}$-ELx800 microplate reader from BioTek Instruments (Winooski, VT, USA). Results were presented as percentage of the control value for untreated cells.

Western blot analysis. Anti-Mdr (G-1; Santa Cruz Biotechnology-13131) monoclonal antibodies directed to a highly conserved epitope of human ABCB1 and monoclonal anti-human MRP1 directed against an epitope of ABCC1 (QCRL-1; Santa Cruz Biotechnology-18835) were used. Total protein lysate $(10 \mu \mathrm{g})$ was loaded onto each lane of a $6 \%$ SDS/polyacrylamide gel and electrophoresis was performed as described by Laemmli (1970). Wide-range molecular mass protein markers $24-180 \mathrm{kDa}$ (Sigma, Germany) were used as a reference. After the transfer onto PVDF membrane and blocking with $5 \%$ not-fat dry milk in PBS overnight at $4{ }^{\circ} \mathrm{C}$, the blots were incubated with anti-Mdr in PBS $(1: 300)$ or anti-human MRP1 antibodies in TBS (1:300), overnight at $4{ }^{\circ} \mathrm{C}$. Secondary antibodies conjugated to horseradish peroxidase (Santa Cruz Biotechnology, USA; 1:3000) and BM Chemiluminescence Western Blotting Kit (Roche Diagnostic, Germany) were used to develop images on autoradiography film (Kodak X-Omat; AR, USA). The loading control was made by immunodetection of $\alpha$-actin (1A4, Santa Cruz Biotechnology-32251).

Flow cytometry. Cultured HeLa cells were incubated with various ionic liquids in three different concentrations as described above. Cells were harvested by trypsinization and fixed for 10 minutes in $2 \%$ formaldehyde (diluted from $37 \%$ stock solution; Sigma, Germany). Icecold methanol (POCh, Poland) was added and the suspension was kept on ice for 30 minutes to bring about permeabilization. Then cells were washed and antibodies against ABCB1 (anti-Mdr, 1:100) or ABCC1 (anti-human MRP1, 1:100) were added and samples were incubated for $1 \mathrm{~h}$ at room temperature. After washing the cells with incubation buffer (Roth, Germany; 0.5\% BSA in PBS), secondary antibodies labeled with AlexaFluor 488 fluorochrome (Molecular Probes, USA; 1:400) were added, followed by $1 \mathrm{~h}$ incubation in the dark. Finally, cells were washed, resuspended in PBS and analyzed by flow cytometry (Beckton Dickinson LSR II).

Statistical analysis. The data from MTT test were expressed as means of three independent experiments conducted in triplicates for each concentration. The results from Western blotting are representatives of 2-7 independent experiments. The data from flow cytometry are means of 5-time repetition of independent experiments conducted in triplicates for each concentration. On this base, standard deviation (S.D.) was calculated. Data were analyzed by two-way ANOVA with appropriate post-hoc tests using Statistica PL software where $P<0.05$ was assumed as statistically significant.

\section{RESULTS}

\section{1-Alkyl-3-methyl-imidazolium ionic liquids are weakly toxic to HeLa cells}

A weak, statistically significant, dose-independent decrease of cell viability was observed upon $72 \mathrm{~h}$ incubation with various IIL in the $10^{-6}-10^{-4} \mathrm{M}$ range (Fig. 1). The elongation of the side carbon chain from $C_{2}$ to $C_{6}$ strengthened this effect. Surprisingly high decrease of cell viability was found after incubation with BeMIMCl, containing a benzene ring.

\section{$A B C B 1$ and $A B C C 1$ are constitutively present in cancer and non-cancer cell lines}

Different levels of the $170 \mathrm{kDa}$ ABCB1 were detected in the cell lines studied (Fig. 2). MCF7 had the highest level, HeLa showed a lower but well visible level and in embryonic HEK293 the protein was undetectable at these conditions and it could only be detected when higher concentration of the primary antibody and

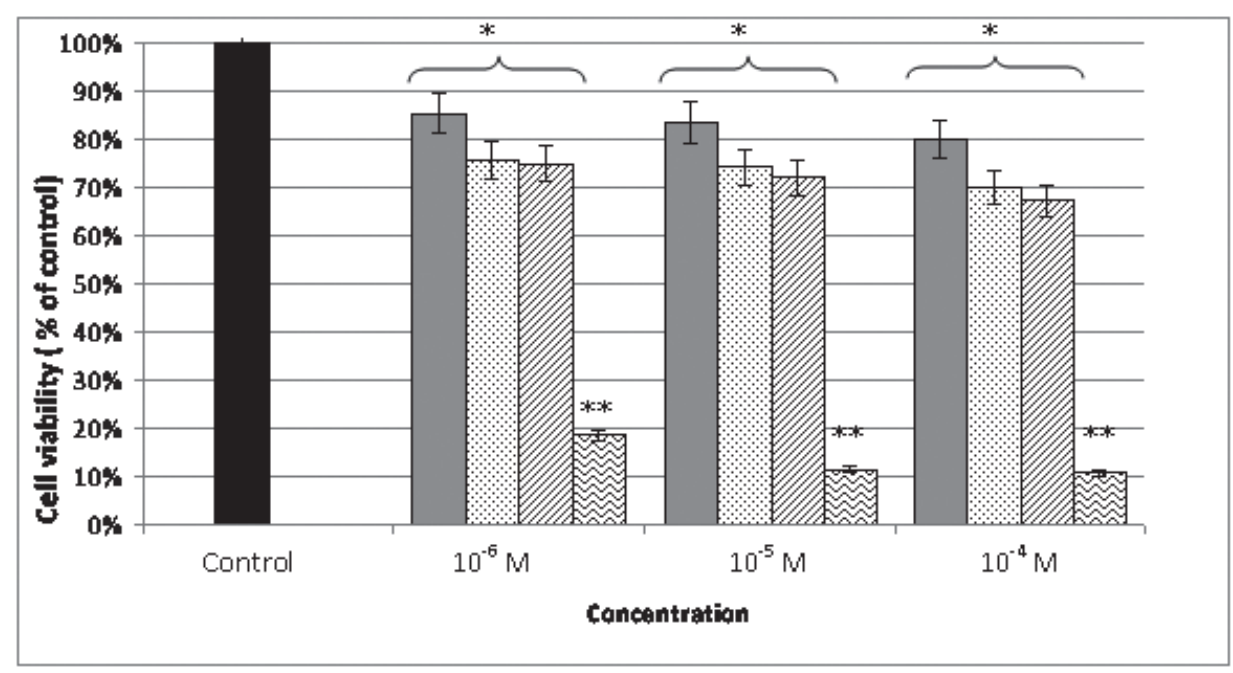

Figure 1. Viability of HeLa cells after 72-h incubation with imidazolium ionic liquids

Control (black); EMIMCI (grey); BMIMCI (dots); HMIMCI (slanted lines); BeMIMCl (wavy lines). All data represent the mean \pm S.D. of three independent experiments conducted in triplicates for each ionic liquid concentration. Differences in viabilities were statistically significant comparing with control $\left({ }^{*} p<0.05\right.$ or $\left.{ }^{* *} p<0.01\right)$. 


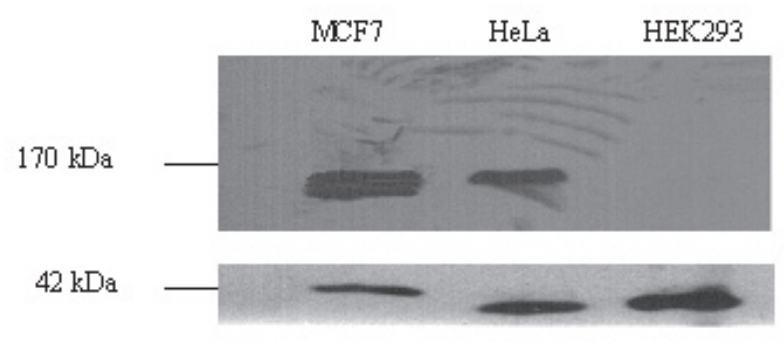

Figure 2. Constitutive presence of $A B C B 1(170 \mathrm{kDa})$ in various cell lines

Lanes loaded with cell extracts from: 1, MCF7; 2, HeLa; 3, HEK293. Aliquots containing $10 \mu \mathrm{g}$ of protein were electrophoresed in $6 \%$ SDS/polyacrylamide gel, transferred on Immobilon-P and incubated with anti-Mdr antibodies $(1: 300)$ in PBS. Actin band of 42 $\mathrm{kD}$ was used as loading control. Figure is representative of at least five experiments.

longer time of film exposure were used (Rusiecka \& Składanowski, 2008). Earlier, a very strong signal of the $190 \mathrm{kDa}$ ABCC1 was also found in cultured MCF7 and HeLa cells (Rusiecka \& Składanowski, 2008).

\section{Exposure of cells to IIL induces both $A B C B 1$ and $A B C C 1$ genes}

Induction of genes coding for ABCB1 and ABCC1 upon prolonged incubation with IILs was checked in HeLa cells. The lower level of constitutive ABCB1 expression in HeLa cells compared to MCF7 cells could allow for its incremental induction. Indeed, 8-day incubation with $10^{-4} \mathrm{M}$ HMIMCl resulted in about 3-fold increase of the ABCB1 $170 \mathrm{kDa}$ band (Fig. 3A). A similar experiment performed with anti-human MRP1 antibodies showed a band at $190 \mathrm{kDa}$ corresponding to ABCC1 at an 8-fold higher level than in the control cells (Fig. 3B).

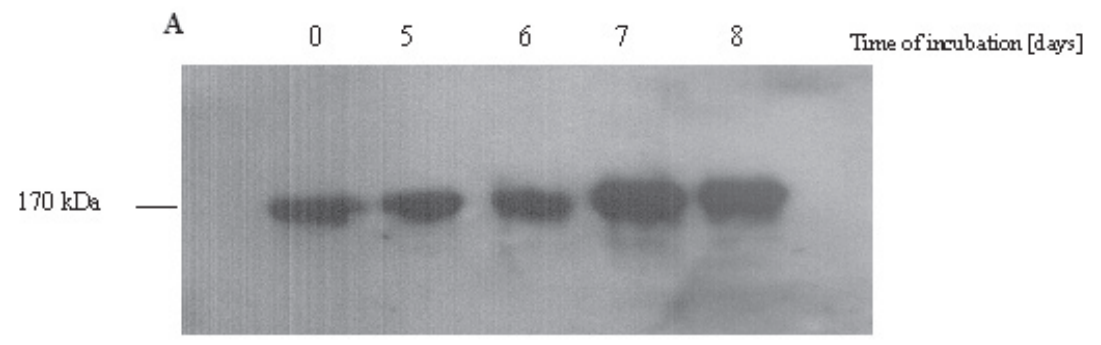

$42 \mathrm{kDa}$
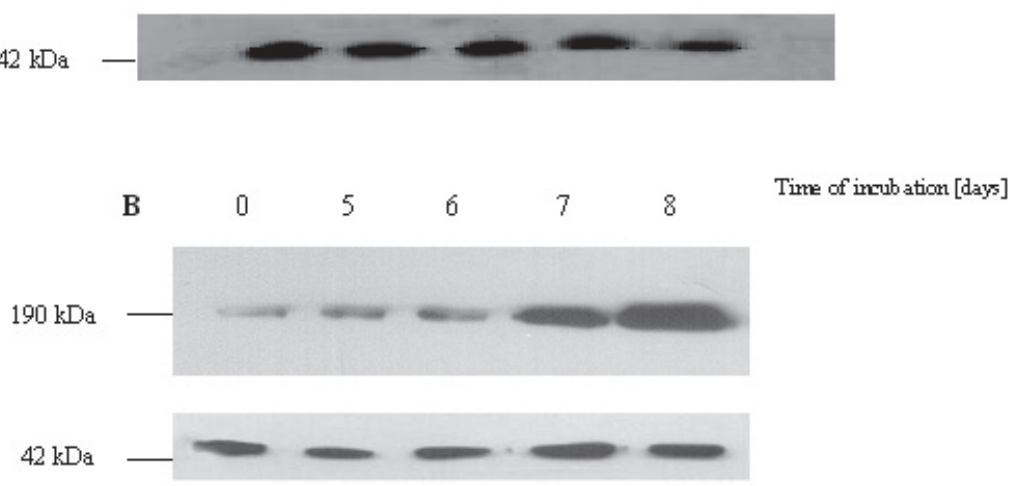

Figure 3. Changes of $A B C B 1$ and $A B C C 1$ in HeLa cells upon incubation with 10-4 M HMIMCl.

Aliquots containing $10 \mu \mathrm{g}$ of protein were electrophoresed in $6 \% \mathrm{SDS} /$ polyacrylamide gel, transferred on Immobilon-P and incubated with anti-Mdr antibodies (1:300) in PBS (Panel A) or anti-human MRP1 $(1: 300)$ in TBS (Panel B). Actin band of $42 \mathrm{kDa}$ was used as loading control. Figure is representative of at least five experiments.
Induction of $A B C B 1$ and $A B C C 1$ in HeLa cells depends on IIL structure

Three homologous IILs together with BeMIMCl were tested by immunoflow cytometry for their impact on the synthesis of the ABC transporters. Significantly elevated fluorescence signals of ABCB1 (Fig. 4A) and ABCC1 (Fig. 4B) were observed in HeLa cells scanned after an 8 -day exposure. The increase was better pronounced at higher concentrations of IIL. An evident correlation with the carbon side chain length was observed for homologous IIL. Whereas the level of ABCB1 after incubation with $10^{-4} \mathrm{M}$ EMIMCl was at the control value, the longer alkyls enhanced ABCB1 expression, up to 2.25-fold with $10^{-4} \mathrm{M} \mathrm{HMIMCl}$. ABCB1 induction by BeMIMCl containing an aromatic ring was observed only at the $10^{-5} \mathrm{M}$ concentration (Fig. 4A).

The increase of fluorescence specific for ABCC1 in HeLa cells after incubation with IIL was even more significant (Fig. 4B). The induction reached 2.1, 2.6 and 3.1-fold after incubation with $10^{-4} \mathrm{M}$ EMIMCl, $\mathrm{BMIMCl}$ and $\mathrm{HMIMCl}$, respectively. The level achieved by BeMIMCl was lower than that for HMIMCl but still high. A dose-effect dependence in the $10^{-6}-10^{-4} \mathrm{M}$ range was observed for all compounds tested.

Summing up, a clear relationship between the amount of $\mathrm{ABCB} 1$ or ABCC1 induced and the length of the side chain in homologous IIL was observed. The aromatic BeMIMCl had a similar effect to $\mathrm{HMIMCl}$ (at least at $10^{-5} \mathrm{M}$ ), however, the much higher toxicity of BeMIMCl

\section{DISCUSSION}

HeLa culture seems to be a convenient model to study induction of genes coding for ABCB1 and ABCC1 of the MDR/MXR system. Earlier we checked the activity of the ion pump in HeLa cells (Rusiecka \& Składanowski, 2008). The intracellular retention of Rhodamine B (a cationic tracer dye, substrate of the ion pump) in the presence of Verapamil (a calcium channel inhibitor and the pump blocker) proved constitutive functionality of this transport. Positively charged ionic liquids are probably transported into the cell by the same mechanism as is Rhodamine B.

However, the constitutive levels of ABCB1, a molecular equivalent of the pump, in various cells were significantly different. Cancerous lines, MCF7 and HeLa, showed much more pronounced signals than the non-cancerous HEK293. The latter one had a minute induction potential for ABCB1 and only after long-time incubation with the toxic compounds. The upregulated ABCB1 protein rapidly returned to the initial level after removal of the inducer (Rusiecka \& Składanowski, 2008). This suggests a self-limiting system in assuring cell homeostasis. 
A

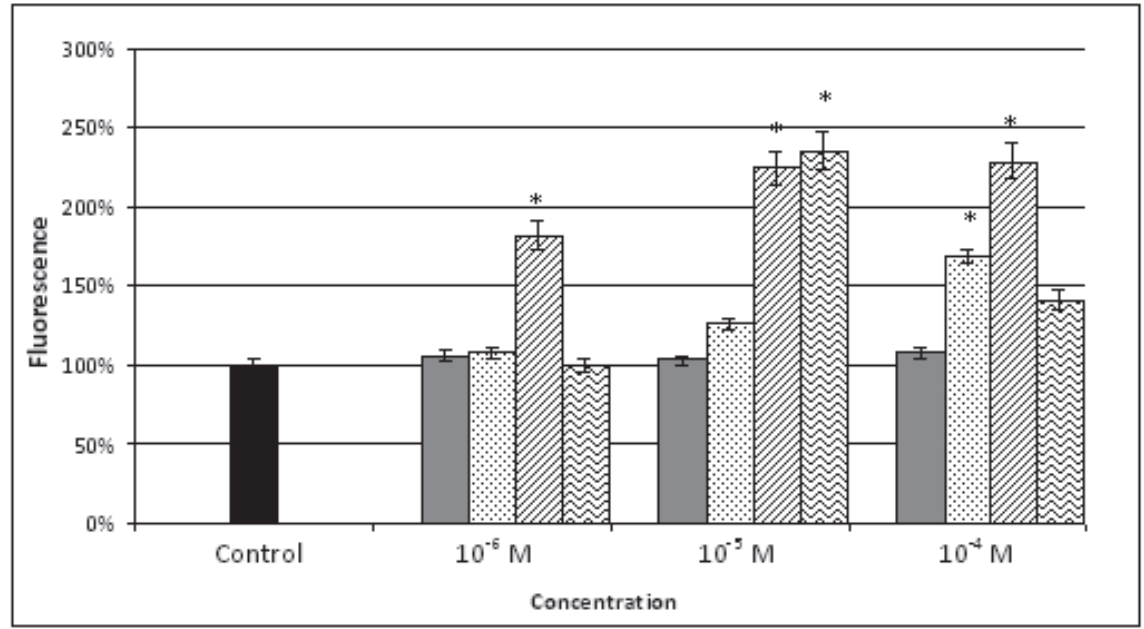

B

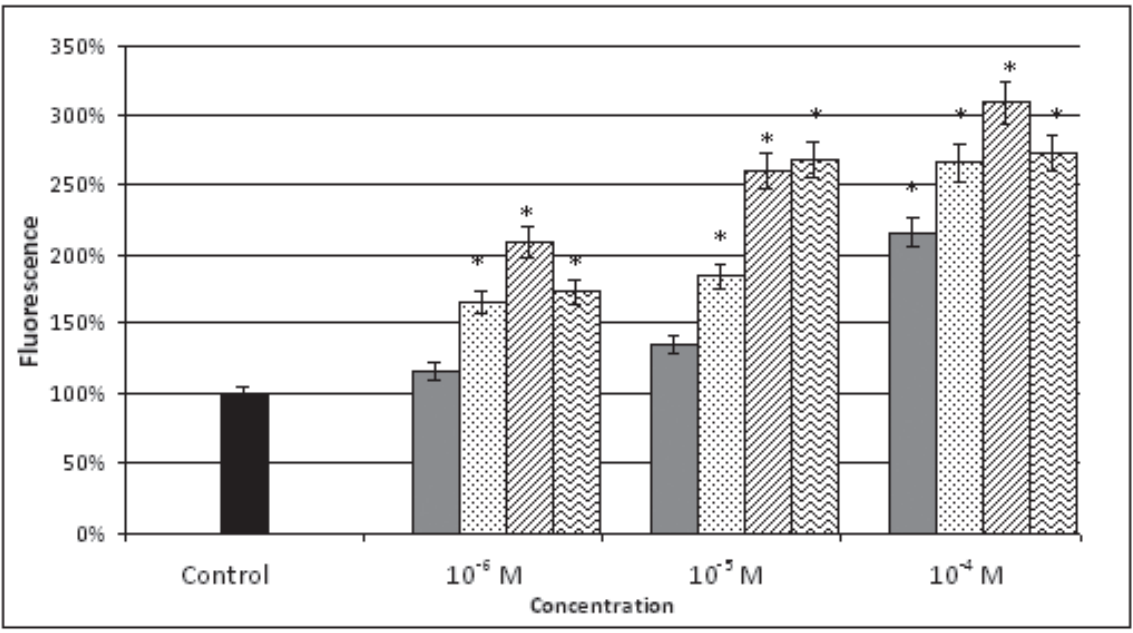

Figure 4. Effect of 8-day incubation of HeLa cells with various imidazolium ionic liquids on the fluorescence of ABCB1 (Panel A) and ABCC1 (Panel B) in flow cytometry

Cells incubated with specific antibodies in the absence of effectors were used as controls (black); EMIMCl (grey); $\mathrm{BMIMCl}$ (dots); $\mathrm{HMIMCl}$ (slanted lines); BeMIMCI (wavy lines). All data represent the mean \pm S.D. of five independent experiments conducted in triplicates for each ionic liquid concentration. Differences in fluorescence were statistically significant comparing with control $\left({ }^{*} P<0.05\right)$.

It was confirmed in this paper that both the total amounts of ABCB1 and ABCC1 and their domains accessible to antibodies in the cell membrane were increasing during 8-day incubation, in particular with HMIMCl. The amounts indicated on Western blots (Fig. 3) were in good agreement with the immunoflow cytometry data (Fig. 4) for ABCB1 (3 and 2.3-fold increase) but in the case of ABCC1 the agreement was poor (8 and 3-fold, respectively, for these two techniques).

We defined the induction potential of the MDR/ MXR system for individual toxic compounds. The increase in the $\mathrm{ABCB} 1 / \mathrm{ABCC} 1$ protein level was related to the IIL toxicity ranked according to the structureactivity relationship (SAR). Our data refer to the toxic properties of IIL based on theoretical SAR considerations and on experiments estimating their biological activity (Jastorff et al., 2003; Ranke et al., 2004; Stepnowski et al., 2004; Stock et al., 2004; Składanowski et al., 2005). All those studies indicated a simple relationship with the elongation of $n$-alkyl chain of IIL increasing their toxicity (Swatloski et al., 2004).

The presented data also show induction of genes coding for the ABCB1/ABCC1 transporters under the influ- ence of homologous compounds based on 1-substituted imidazolium ring. Naturally, these results do not preclude using various IILs in drug synthesis. They rather draw attention to their potential toxicity and indicate necessity of monitoring their presence in the final products. One should pay attention to the induction of cell resistance to drugs contaminated with IILs in vivo as it might reduce the effectiveness of therapy. Our data propose HeLa cells as a system of choice in assays for induction of $\mathrm{MDR} / \mathrm{MXR}$.

\section{REFERENCES}

Chaudhary PM, Roninson IB (1993) Induction of multidrug resistance in human cells by transient exposure to different chemotherapeutic drugs. I Natl Canc Inst 85: 632-639.

Chin KV, Tanaka S, Darlington G, Pastan I, Gottesman MM (1990) Heat shock and arsenite increase expression of the multidrug resistance (MDR1) gene in human renal carcinoma cells. J Biol Chem 265: 221-226.

Cole SP, Sparks KE, Fraser K, Loe DW, Grant CE, Wilson GM, Deeley RG (1994) Pharmacological characterization of multidrug resistant MRP-transfected human tumor cells. Cancer Res 54: 5902-5910.

Cordon-Cardo C, O’Brien JP, Boccia J, Casals D, Bertino JR, Melamed MR (1990) Expression of the multidrug resistance gene product (P- 
glycoprotein) in human normal and tumor tissues. I Histochem Cytochem 38: 1277-1287.

Deeley R, Cole S (2006) Substrate recognition and transport by multidrug resistance protein 1 (ABCC1). FEBS Lett 580: 1103-1111.

Endicott JA, Ling V (1989) The biochemistry of P-glycoprotein-mediated multidrug resistance. Ann Rev Biochem 58: 137-171.

Gottesman MM, Pastan I (1993) Biochemistry of multidrug resistance mediated by the multidrug transporter. Ann Rev Biochem 62: 385427.

Higgins CF (1992) ABC transporters: from microorganisms to man. Ann Rev Cell Biol 8: 67-113.

Jastorff B, Störmann R, Ranke J, Mölter K, Stock F, Oberheitmann B, Hoffman W, Hoffmann J, Nüchter M, Ondruschka B, Filser J (2003) How hazardous are ionic liquids? Structure-activity relationships and biological testing as important elements for sustainability evaluation. Green Chem 5: 136-142.

Laemmli UK (1970) Cleavage of structural proteins during the assembly of the head of bacteriophage T4. Nature 227: 680-685.

Liu FH, Jiang Y (2007) Room temperature ionic liquid as matrix medium for the determination of residual solvents in pharmaceuticals by static headspace gas chromatography. J Chromatogr A 1167: 116-119.

Mizuuchi H, Jaitely V, Murdan S, Florence AT (2008) Room temperature ionic liquids and their mixtures: potential pharmaceutical solvents. Eur J Pharm Sci 33: 326-331.

Park JG, Kramer BS, Steinberg SM, Carmichael J, Collins JM, Minna JD, Gazdar AF (1987) Chemosensitivity testing of human colorectal carcinoma cell lines using a tetrazolium-based colorimetric assay. Cancer Res 47: 5875-5879.

Ranke J, Mölter K, Stock F, Bottin-Weber U, Poczobutt J, Hoffmann J, Ondruschka B, Filser J, Jastorff B (2004) Biological effects of imidazolium ionic liquids with varying chain lengths in acute $V i$ brio fischeri and WST-1 cell viability assays. Ecotoxicol Environ Saf 58: $396-404$.
Rusiecka I, Składanowski AC (2008) Induction of the multixenobiotic/ multidrug resistance system in various cell lines in response to perfluorinated carboxylic acids. Acta Biochim Pol 55: 329-337.

Seelig A (1998) A general pattern for substrate recognition by P-glycoprotein. Eur J Biochem 251: 252-261.

Składanowski AC, Stepnowski P, Kleszczyński K, Dmochowska B (2005) AMP deaminase in vitro inhibition by xenobiotics. A potential molecular method for risk assessment of synthetic nitro- and polycyclic musks, imidazolium ionic liquids and N-glucopyranosyl ammonium salts. Environ Toxicol Pharmacol 19: 291-296.

Stepnowski P, Składanowski AC, Ludwiczak A, Lączyńska E (2004) Evaluating the cytotoxicity of ionic liquids using human cell line HeLa. Hum Exp Toxicol 23: 513-517.

Stock F, Hoffmann J, Ranke J, Störmann R, Ondruschka B, Jastorff B (2004) Effects of ionic liquids on the acetylcholinesterase - a structure-activity relationship consideration. Green Chem 6: 286290.

Swatloski RP, Visser AE, Reichert WM, Broker GA, Farina LM, Holbrey JD, Rogers RD (2001) Solvation of 1-butyl-3-imidazolium hexafluorophosphate in aqueous ethanol - a green solution for dissolving hydrophobic ionic liquids. Chem Commun 20: 2070-2071.

Swatloski RP, Holbrey JD, Memon SB, Caldwell GA, Rogers RD (2004) Using Caenorhabditis elegans to probe toxicity of 1-alkyl-3methylimidazolium chloride based ionic liquids. Chem Commun 6: 668-669.

Uchiumi T, Kohno K, Tanimura H, Matsuo K, Sato S, Uchida Y, Kuwano M (1993) Enhanced expression of the human multidrug resistance 1 gene in response to UV light irradiation. Cell Growth Differ 4: $147-157$.

Welton T (1999) Room-temperature ionic liquids. Solvents for synthesis and catalysis. Chem Rev 99: 2071-2083.

Zhao D, Liao Y, Zhang Z (2007) Toxicity of ionic liquids. Clean 35: $42-48$. 